\title{
60th ANNIVERSARY OF THE STARTUP OF THE WORLD'S FIRST NUCLEAR POWER PLANT IN OBNINSK
}

Sixty years have passed since the first nuclear plant was started up. Today, we recognize that the creation of the world's first nuclear power plant in Obninsk and the conquest of the atom are the greatest achievements of mankind in understanding the universe and penetrating into nature's secrets, prepared by all the preceding advances in physics. Great names, discoveries, constellations of talents, examples of selflessness and dedication to physics stand behind this event. The scientists travelled along a very difficult road from misgivings that in studying the atom it might be possible to accidently blow up the entire world to confidence that a controlled nuclear chain reaction is realizable and can be a blessing for mankind.

The power of the first nuclear power plant, built in Obninsk on the site of Laboratory V, which at the time was called the Institute for Physics and Power Engineering, was low even by the standards of that time. Nonetheless, the startup of this plant was a unique technological achievement. The political significance of this event was also extraordinarily great. Indeed, against the background of the arms race, a race that took many a twist and turn, our country, which still had not recovered from an extremely destructive war, found the strength within itself not only to develop defensive nuclear weapons but also to propose an alternative to the world by setting a real example of a constructive application of atomic energy.

This is why the participants of the First International Conference on the Peaceful Uses of Atomic Energy in Geneva in 1955, going against the established order, greeted with standing ovation the report by the Soviet delegation on the development and startup of the first nuclear power plant, and the world perceived this event as epochal. The first nuclear power plant will forever remain in the history of science as a noble landmark in mankind's striving toward happiness and prosperity.

The enormous technical experience gained in operating the first nuclear power plant and the extensive experimental material have served as a foundation for the subsequent advancement of nuclear power, coming into fruition in the development of water-moderated, water-cooled and water-graphite reactors of medium and high power (VVER-500, -1000, VPBER-600, MKER-800).

Another enormous line of scientific and technical work by nuclear scientists and engineers was the development of liquid-metal fast reactors based on a new technological platform which is based on a closed nuclear fuel cycle with fast reactors. The development of these reactors is a shining page in the history of nuclear power.

Articles devoted to the advances in the development of fast reactors written by scientists and specialists at the State Science Center of the Russian Federation - Leipunskii Institute for Physics and Power Engineering (GNTs RF - FEI) are published in the present and next issues of this journal.

Translated from Atomnaya Énergiya, Vol. 116, No. 4, p. 183, April, 2014. 